\title{
JOVENS CEGOS TATEANDO OS SEUS PROJETOS DE VIDA UM ESTUDO SOBRE SUAS REPRESENTAÇÕES
}

\author{
YOUNG BLIND FEELING YOUR LIFE PROJECTS \\ A STUDY ON THEIR REPRESENTATIONS
}

\section{JÓVENES CIEGOS QUE SIENTEN TUS PROYECTOS DE VIDA UN ESTUDIO SOBRE SUS REPRESENTACIONES}

Ivany Pinto Nascimento ${ }^{1}$; Lourival Nascimento ${ }^{2}$

\begin{abstract}
RESUMO
O artigo objetiva apresentar os resultados parciais do estudo desenvolvido no período de 2017 a 2018, com os seguintes questionamentos: como os jovens com cegueira que moram na Amazônia paraense, região Norte do País, compartilham conhecimentos sobre seus Projetos de Vida e qual a importância que atribuem à escola para a realização desses projetos? Trata de uma pesquisa de abordagem processual, do campo teórico e metodológico das Representações Sociais. O instrumento utilizado foi a entrevista com roteiro preestabelecido em forma de temáticas sobre o projeto de vida. Os sujeitos entrevistados foram 10 jovens cegos estudantes, distribuídos igualmente entre jovens do sexo feminino e jovens do sexo masculino na faixa etária entre 15 a 29 anos, vinculados a Unidade Técnica Educacional Especializada José Álvares de Azevedo (UTES JAA). A Análise de Conteúdo de Bardin (1997) foi utilizada para identificar o pensamento consensual de jovens cegos sobre seus projetos de vida. Os resultados parciais apontam o seguinte: que as representações sociais refletem as imagens e os significados sobre o projeto de vida que transitam entre Educação, Trabalho; que a escola, sem ressignificar a racionalidade com a qual materializa o processo de ensino-aprendizagem, passa a representar um obstáculo tanto na inclusão escolar quanto na realização de seus projetos de vida.
\end{abstract}

PALAVRAS-CHAVE: Juventude. Diversidade. Representações.

\footnotetext{
${ }^{1}$ Doutora e Pós Doutora em Psicologia da Educação - Pontifícia Universidade Católica de São Paulo (PUC/SP). Docente e Pesquisadora do Instituto de Educação e da Pós-graduação em Educação da Universidade Federal do Pará (UFPA). Belém, PA - Brasil. Coordenadora do Grupo de Estudos e Pesquisa sobre Juventude, Representações Sociais e Educação. Bolsista Produtividade CNPq. E-mail: ivany.pinto@gmail.com ${ }^{2}$ Mestre em Planejamento do Desenvolvimento Sustentável e Doutorando - Universidade Federal do Pará (UFPA). Belém, PA - Brasil. Professor na Secretaria do Estado da Educação (SEDUC). Assessor pedagógico de educação inclusiva na Secretaria Municipal de Educação de Belém. Belém, PA - Brasil. E-mail:

lourivalnascimento1@gmail.com
}

Submetido em: 27/11/2019 - Aceito em: 28/04/2020

$\begin{array}{llllll}\text { (C) ETD-Educação Temática Digital } & \text { Campinas, SP } & \text { v.23 } & \text { n.3 } & \text { p.716-738 } & \text { jul./set.2021 }\end{array}$




\section{ABSTRACT}

The article aims to present the partial results of the study conducted from 2017 to 2018, with the following questions: how young people with blindness who live in the Paraense Amazon, northern region of the country, share knowledge about their Life Projects and how important it is assign to the school to carry out these projects? It deals with a research of procedural approach, the theoretical and methodological field of Social Representations. The instrument used was the interview with pre-established script in the form of themes about the life project. The subjects interviewed were 10 young blind students, equally distributed among young women and young men aged 15 to 29 years, linked to José Álvares de Azevedo Specialized Educational Technical Unit (UTES JAA). Bardin's Content Analysis (1997) was used to identify the consensus thinking of blind young people about their life projects. The partial results point to the following: that social representations reflect the images and meanings about the life project that transit between Education, Work; that the school, without reframing the rationality with which the teaching-learning process materializes, now represents an obstacle to both school inclusion and the achievement of its life projects.

KEYWORDS: Youth. Diversity. Representations.

\section{RESUMEN}

El artículo tiene como objetivo presentar los resultados parciales del estudio realizado entre 2017 y 2018 , con las siguientes preguntas: cómo los jóvenes con ceguera que viven en la Amazonía Paraense, en la región norte del país, comparten conocimientos sobre sus proyectos de vida y cuán importante es asignar a la escuela para llevar a cabo estos proyectos? Se trata de una investigación del enfoque procesal, el campo teórico y metodológico de las representaciones sociales. El instrumento utilizado fue la entrevista con guión preestablecido en forma de temas sobre el proyecto de vida. Los sujetos entrevistados fueron 10 jóvenes estudiantes ciegos, distribuidos equitativamente entre mujeres jóvenes y hombres jóvenes de 15 a 29 años, vinculados a José Álvares de Azevedo Unidad Técnica Educativa Especializada (UTES JAA). El Análisis de contenido de Bardin (1997) se utilizó para identificar el pensamiento consensuado de los jóvenes ciegos sobre sus proyectos de vida. Los resultados parciales apuntan a lo siguiente: que las representaciones sociales reflejan las imágenes y los significados sobre el proyecto de vida que transitan entre Educación, Trabajo; que la escuela, sin reformular la racionalidad con la que se materializa el proceso de enseñanza-aprendizaje, ahora representa un obstáculo tanto para la inclusión escolar como para el logro de sus proyectos de vida.

PALAVRAS-CLAVE: Juventud. Diversidad. Representaciones.

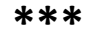

\section{INTRODUÇÃO}

Os estudos sobre a juventude no Brasil se constituem em um campo muito vasto de produções, uma vez que a juventude se subdivide em grupos socioculturais que se diferenciam em suas dinâmicas e permeiam suas identidades, assim como formas de ir e vir no mundo e com o mundo.

Pensar a juventude sem considerar essa diversidade é desconsiderar o tempo e o espaço das suas construções. Significa que, como afirma Farias (2018, p. 104) - em seu estudo de doutoramento, ao abordar as representações sociais de jovens da Amazônia paraense, sobre suas escolarizações e as implicações nos seus projetos de vida, estes que, quando tratamos de juventude - devemos considerar, visto que: "Sua constituição sempre esteve atrelada a questões sociais, econômicas e mesmo políticas, logo, qualquer tentativa de compreensão que descarte essas características é inválida".

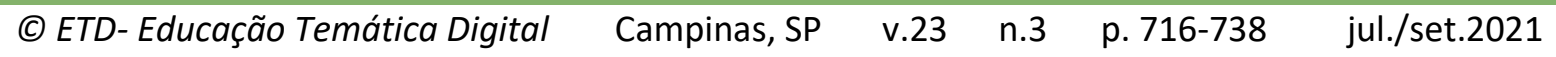


A pesquisadora mencionada reforça o nosso pensamento ao afiançar que a juventude é construída em um contexto socioeconômico e político e é a partir dele que os sentidos que caracterizam a diversidade de jovens se delineiam. Acrescentamos, ainda, o aspecto histórico desse contexto, pois é ele quem integra e articula os demais contextos, além de ser um forte determinante geracional.

Podemos, então, asseverar, conforme já fizeram alguns teóricos, que a juventude é uma condição histórico-social (PERALVA, 1997). Mesmo que existam sinalizadores na juventude e imprimam características universais, a forma como cada grupo de jovens lida com essas características é diferente, pois depende, como já mencionamos, do contexto histórico-social em que esse grupo se encontra inserido.

Quanto à faixa etária considerada, o Estatuto da Juventude, instituído pelo Governo Federal pela Lei $n$ o 12.852/2013, considera jovem toda pessoa que esteja com idades entre 15 a 29 anos (BRASIL, 2013).

Constatamos, mesmo com uma faixa etária estabelecida para situar onde inicia e onde termina a juventude, que a compreensão do que é ser jovem extrapola os parâmetros determinados pela faixa etária. Por exemplo, no Brasil, existem crianças que assumem funções de jovens ou até mesmo de adultos, assim como jovens que assumem papéis de adultos. Essas e outras situações que caracterizam as juventudes brasileiras se inscrevem, com maior frequência, em determinadas regiões brasileira e em determinadas classes econômicas e sociais.

Dayrell (2007) argumenta que a construção da noção de juventude na perspectiva plural deve considerar as suas singularidades que se delineiam a partir das experiências e da interação com seu contexto social.

Dessa forma, Raitz e Petters (2008) destacam que o conceito de juventude não tem uma definição estática, variando, em cada momento histórico, em cada fase geracional, influenciada pelo contexto social, comportando-se e pensando de formas diferenciadas e singulares. Ressaltamos que os teóricos em seus estudos sobre os novos desafios para a juventude no século XXI consideram a perspectiva histórica, social e cultural para explicitar a temática que engendra a juventude.

Nesse sentido, as juventudes têm marcas que constituem suas identidades em diferentes momentos históricos, constroem representações sobre si, sobre os outros e sobre o mundo social. Essas representações, caracterizadas por Moscovici (1978), como sociais, uma vez que se compõem a partir das trocas e negociações entre os jovens do grupo sobre os sentidos que norteiam seus pensamentos, seus sentimentos e suas ações em um dado momento histórico. Farias (2018) assegura com propriedade que:

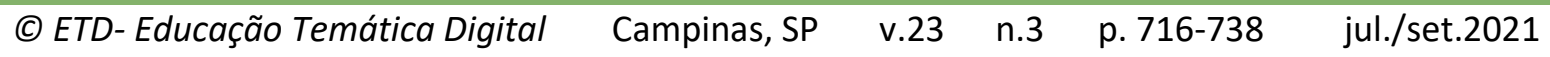


Isso demonstra que o pensamento sobre a identidade juvenil vem, ao longo da história, passando por várias modificações em função das próprias transformações que ocorreram na sociedade e que incidem completamente na forma como os jovens se constroem, e são representados. (FARIAS, 2018, p. 104).

Carrano (2003) considera que ao se desenvolver estudos sobre a juventude, precisamos nos libertar dos estereótipos sobre essa categoria social que, sem dúvida, nos colocam distantes da compreensão de juventudes que extrapolam essas classificações e rótulos. Por exemplo, ao pensarmos nos jovens e nas jovens que moram na Amazônia paraense e os contextos, sociais, culturais, econômicos, políticos e outros que se entrelaçam a construção dessas juventudes, consideramos Sui generis, ou seja, bem diferentes do que comumente a mídia informa sobre as juventudes brasileiras. Isso faz com que se silencie a existência de outras juventudes no território brasileiro. Dessa maneira, essas juventudes passam a fazer parte dos grupos sociais de jovens que vivem à margem, pois não são contemplados em suas necessidades e nem incluídos socialmente.

Dentre essas juventudes, em nossa Amazônia paraense, que representam a diversidade de nosso país, temos as que se denominam da seguinte forma: as das águas, as das florestas, as dos campos, as dos assentamentos, as ribeirinhas, as indígenas, as quilombolas, dentre outras, cujas denominações se vinculam aos seus territórios. Segundo Oliveira e Hage (2011), para essas juventudes, a dimensão territorial deve ser problematizada e analisada, pois ela se vincula a dimensão social, cultural, educacional etc.

Outro ponto que merece destaque, viso que é o ponto central de nosso estudo, é o de que nessas e noutras juventudes existem outros grupos juvenis constituídos, cujos agrupamentos ocorrem pelas necessidades especiais que têm em função da deficiência física, visual, auditiva, intelectual, dentre outras. Esses grupos merecem estudos para o aprofundamento das suas características e necessidades, em prol de políticas e programas que promovam o acompanhamento, o desenvolvimento, a aprendizagem, a socialização e a inclusão social e escolar, fundamentais para que esses jovens superem as limitações impostas pela deficiência.

No caso de jovens $\operatorname{cegos}^{3}$ que moram na cidade de Belém, alvo de nosso estudo, consideramos como mais um exemplo daquelas juventudes que, mesmo enfrentando dificuldades de reconhecimento social e escolar frente às suas necessidades e aspirações, não se deixam abalar no sentido de romper barreiras tanto sociais quanto escolares.

\footnotetext{
${ }^{3}$ Denominamos cegos aqueles jovens com perda total da capacidade visual.
}

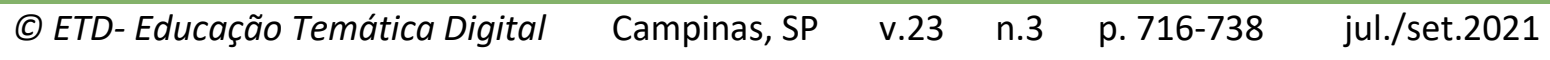


Ao intencionarmos enveredar pela investigação das representações sociais de jovens cegos sobre seus projetos de vida e a importância que atribuem à escola para a realização desses projetos, consideramos fundamental ouvir esses jovens para poder apreender as representações sociais que têm sobre seus projetos de vida, na medida em que, essas representações orientam seus pensamentos, sentimentos e ações em seus contextos de vida, de existência e com seus projetos de vida. Concebemos que esse é o caminho para ampliarmos a compreensão sobre esses jovens, uma vez que as produções científicas sobre a juventude cega tanto local quanto nacional são ainda incipientes. Muito embora, o autor e pesquisador deste estudo, partilhe com esses jovens, alvo do estudo, da mesma deficiência, mas entendemos que a singularidade desses grupos não pode ser substituída e esquecida.

A referência teórica-metodológica adotada, neste estudo, foi a das representações sociais, criada pelo psicólogo romeno, naturalizado francês Serge Moscovici, a partir dos estudos elaborados para a sua tese de doutoramento e mais tarde transformada em livro intitulado: La psychanalise, son image et son public (1978). Moscovici (1978) se preocupava com o poder que o conhecimento do senso comum tem na vida dos grupos sociais. Esse conhecimento, que orienta pensamentos, sentimentos e ações de grupos, é resultado da comunicação feita nas interações sociais.

Com base em Moscovici (1978), as interações sociais que estabelecemos no dia a dia produzem saberes compartilhados que passam a orientar pensamentos, sentimentos e ações. Esses saberes ultrapassam a razão formal, aquela que se vincula ao fato propriamente dito. Desse modo, o campo psicossocial responsável pelas construções cognitivas só pode ser apreendido com base no contexto que o engendra e dos lugares que ocupa nas interações sociais do cotidiano (JODELET, 2001).

A apreensão dessas construções de pensamento, advindas do senso comum, é que permitem explicar as ações dos grupos sobre o mundo social. A realidade, portanto, é construída a partir desse conhecimento do cotidiano. Pierre Bourdieu (1989, p.444) ratifica o nosso pensamento ao dizer que "a representação que os indivíduos e os grupos exibem inevitavelmente por meio de suas práticas e propriedades faz parte integrante de sua realidade social".

Jodelet (2001) e Moscovici (2011, p.2 7) asseveram que a "representação é sempre uma representação de alguém e ao mesmo tempo representação de alguma coisa". Significa dizer que a representação na perspectiva moscoviciana só pode se constituir a partir das interações sociais entre sujeitos sobre um objeto e/ou acontecimento existente naquele grupo e/ou sociedade. 
Nesse sentido, a Teoria das Representações Sociais, na perspectiva processual, se inscreve, neste estudo, uma vez que possibilita apreender os dois elementos, a objetivação e a ancoragem, que constituem os processos de elaboração e formação das representações sociais. Tanto a objetivação quanto a ancoragem organizam uma rede simbólica e valorativa de conhecimentos consensuados entre grupos sociais sobre os sujeitos, os objetos, os acontecimentos e os fazeres do cotidiano (MOSCOVICl, 2002).

As representações sociais, afirma Moscovici (2007):

[...] sempre possuem duas faces, que são interdependentes, como duas faces de uma folha de papel: a face icônica e a face simbólica. Nós sabemos que: representação = imagem/significação; em outras palavras, a representação iguala toda imagem a uma ideia e toda ideia a uma imagem. (MOSCOVICl, 2007, p. 46).

A objetivação é concebida pelo mentor da teoria da seguinte forma: "faz com que se torne real um esquema conceptual, com que se dê a uma imagem uma contrapartida material [...]" (MOSCOVICl, 1978, p. 110). Na objetivação, o pensamento 'lança mão' da naturalização para tornar concretos e reais, conceitos abstratos.

$\mathrm{Na}$ ancoragem, o pensamento elabora sentidos às imagens objetivadas, fazendo com que os fenômenos sociais até então não-familiares se transformem em familiar ao grupo. Nessa lógica, como nos diz Spink (1993, p. 306), "ancoramos o desconhecido em representações já existentes e concebida como processo cognitivo intra-individual".

Nessa perspectiva, a ancoragem atribui sentido à imagem da representação. Esse sentido varia de acordo com o as partilhas do grupo de pertença e com os seus valores.

A importância de estudarmos as representações sociais sobre o projeto de vida pelo grupo de jovens cegos, reside na afirmativa de que esses conhecimentos sobremaneira orientam as ações desses sujeitos, além de sinalizarem questões sobre suas demandas na perspectiva da inclusão escolar, considerada, por nós, como um direito de todos, afora a escola ser uma instituição fundamental na formação do sujeito-cidadão, no desenvolvimento de habilidades para a vida e na preparação para o trabalho. Vale lembrar, que o Decreto no 5.296, de 2004, artigo 24 que determina que as escolas proporcionem condições de acessos e a utilização de todos os espaços do estabelecimento por todos os que as frequentam (BRASIL, 2004), ratifica a importância da escola na vida desses jovens cegos.

A referência de Inclusão escolar que utilizamos é a de que ela é um processo que visa apoiar a educação para todos e para cada criança no mundo (AINSCOW; FERREIRA, 2003). Essa educação implica não somente acolher os alunos com deficiência na escola, mas também proporcionar condições de acesso e de aprendizagem em todos os espaços, programas e as atividades no cotidiano escolar (BERSCH et al, 2011). Significa acolher esses

$\begin{array}{llllll}\text { (C) ETD-Educação Temática Digital } & \text { Campinas, SP } & \text { v.23 } & \text { n.3 } & \text { p.716-738 } & \text { jul./set.2021 }\end{array}$


sujeitos, independentemente de cor, classe social, orientação sexual, religião e condições físicas e psicológicas.

Segundo Correia (1999, p. 14), "a escola está à disposição de todas as crianças em igualdade de condições e é obrigação da comunidade proporcionar-lhes um programa público gratuito de educação adequado às suas necessidades".

Nessa linha de pensamento, ponderamos que se sentir incluído é ter um sentimento de pertença a um grupo e/ou a uma instituição escolar, ou seja, é desenvolver interações com a escola que o leve ao pertencimento, à credibilidade, ao crescimento, à empatia, ao protagonismo para realizar seu projeto de vida. A escola, por sua vez, deve responder na mesma sintonia, responsabilizando-se pelo aluno, acolhendo-o, acreditando no seu desenvolvimento, na sua aprendizagem, no seu crescimento e protagonismo na escola e na sua vida. Para tanto, é fundamental que a escola conheça seus alunos, suas demandas, suas necessidades específicas, suas dificuldades, suas culturas, enfim, suas histórias. A partir daí, a escola pode pensar refletir e planejar suas ações e suas práticas pedagógicas e metodológicas.

Possivelmente, a escuta, a observação e a interação com o outro diferente aumentam as possibilidades de apreender e compreender seus pensamentos, suas representações, suas emoções, suas ações dentre outros aspectos que impõem formas de existir, de representar e de objetivar os seus projetos de vida, temática utilizada, neste estudo, com o seguinte entendimento, de acordo com Nascimento (2002):

[...] o sentido de aspirações, desejos de realizações, que se projetam para o futuro como uma visão antecipatória de acontecimentos, cuja base reside em uma realidade construída na inserção das relações que o sujeito estabelece com o mundo. (NASCIMENTO, 2002, p. 35).

Catão (2001) acrescenta que o projeto de vida é um conjunto de intenções e de realizações que considera a relação entre passado e presente para a perspectiva de futuro e é orientado pelas representações de mudanças e bem-estar.

Nascimento (2018) complementa a concepção da autora da seguinte forma:

A perspectiva de futuro é também uma forma de dar-se a conhecer para si e para os outros por meio dos anseios, planos de vida e da ampliação de possibilidades que articulam realizações, tais como: possuir uma profissão, um trabalho, casar, ter filhos, ter acesso aos bens de consumo casa, carro, apartamento etc. (NASCIMENTO, 2018, p. 10).

Consideramos que no Brasil ainda somos devedores da inclusão social e escolar de todos os grupos, sobretudo daqueles com muito mais limitações e esquecidos. Com o grupo de cegos, a exclusão não é tão diferente da de outros grupos de sujeitos com deficiência.

(C) ETD-Educação Temática Digital Campinas, SP $\quad$ v.23 $\quad$ n.3 $\quad$ p.716-738 jul./set.2021 
Desse modo, a inclusão ainda não se constitui em uma realidade social na vida da maioria desses sujeitos.

Os preconceitos sobre o sujeito cego ainda continuam a existir na sociedade, perpetuando a história de que o deficiente visual não é capaz de desenvolver habilidades e construir conhecimentos que permitam a ele protagonizar sua vida e seus projetos. Esses e outros clichês que pesam sobre a juventude cega causam sofrimentos, desestímulo e descrença sobre os tempos presente e futuro, ao invés de acolher, solidarizar e ajudar esses jovens a superarem as dificuldades inerentes da cegueira. Acrescentamos a isso, a incorporação desses estereótipos pelo jovem cego o que causa para a maioria o sentimento de inutilidade do que o sentimento de desafio e de luta.

Reiteramos que o sentimento de inutilidade e baixa autoestima desses grupos se acentuam em função das crenças, valores e ideologias instituídos, ao longo da história da civilização. Esses pseudo saberes foram partilhados e disseminados entre os grupos sociais e se transformaram em representações sociais que serviram para domínio e poder instituído de uma época.

A dimensão emocional influencia, em grande medida, no pensamento e nas ações desses sujeitos cegos. Essa dimensão entrelaçada a outras, como: a cognitiva, as das ações e a do social vão guiar o processo de subjetivação do jovem cego, influenciando diretamente no seu modo de existir e interagir no e com o mundo

A história somente se ressignifica e se transforma se, inicialmente, aqueles que a fazem iniciarem esse processo. Assim, podemos dizer que os sentidos que sustentam representações e imprimem estigmas podem se transformar, caso tivermos a coragem de revê-los e reconhecê-los que existe vida em todos e para todos. Todos desejam viver o pertencimento social e escolar, saber que o estado de direito se responsabiliza por todos, independente do credo, da etnia, da orientação sexual, da religião, das necessidades específicas etc. Cada sujeito deve ser tratado pelo estado como um cidadão que tem os direitos e deveres; tem também o direito também ir e vir; de protagonizar a sua história, utilizando suas potencialidades; aprendizagens escolares e de vida.

Esses rótulos que se perpetuam em nossa contemporaneidade e impedem que a sociedade avance e aprimore suas interações e formas de tratar o outro diferente. Impede também que as políticas de inclusão se estabeleçam e se transformem em realidade. Essa forma preconceituosa de lidarmos com o diferente prejudica também todos os sujeitos, pois deixamos de interagir, de aprender com o outro e aprimorar nossas formas de pensar, sentir e agir humanos e tornar o nosso país mais justo e mais inclusivo. 
Duarte (2015) garante que:

Atitudes assim só reforçam o preconceito e autorizam direta ou indiretamente os mais diferentes tipos de violências cada vez mais comuns nas escolas e que só são experienciadas e realmente percebidas por aqueles que sentem na pele a dor, o ressentimento e o sofrimento [...]. (DUARTE, 2015, p. 38).

Nesse sentido é oportuno retomar os estudos desenvolvidos por Vygotsky (1989), quando argumenta que a compensação da cegueira não se processa por meios puramente biológicos, ideia que sustenta que o sujeito cego substitui a falta de um sentido por outro (visão pelo tato, pela audição, pelo olfato), antes destaca que a compensação se processa por meios psíquicos-sociais, com ênfase na linguagem e do uso de signos.

Mendes (2014) afiança que a superação da cegueira é buscada pela compensação social, ou seja, por meio da apropriação das experiências daqueles que enxergam, com o uso máximo das possibilidades da linguagem. esta autora declara:

[...] a compensação é o que vem do social e da linguagem, ou seja, dá - se pelo social, e não só pelo biológico. A compensação é de natureza sócio- psicológica e está atrelada aos caminhos alternativos, caminhos sociais. (MENDES, 2014, p. 21).

O sujeito com cegueira mobiliza mecanismos compensatórios para vencer as limitações impostas pela incapacidade da visão, identificando e utilizando os meios que o ambiente físico e social possibilita, seja pela interação interpessoal, ou pelo uso dos signos linguísticos para aceder ao conhecimento e a cultura.

Com base nesse cenário, perguntamos, então: qual o número e o percentual de jovens com cegueira no Brasil? E no Pará? Qual a região do Pará com número maior de jovens cegos? Quais as políticas e programas educacionais de inclusão para jovens cegos?

Ao buscar essas e outras respostas relativas ao mapeamento em números de jovens cegos necessários para reflexões sobre o tema, a primeira constatação a que chegamos refere-se às dificuldades em encontrar informações sistematizadas que nos auxiliassem nesses questionamentos.

Os dados sobre as pessoas com cegueira e com deficiência carecem de atualização e são de difícil acesso. As informações oficiais sobre o total de jovens cegos brasileiros e suas respectivas regiões são vagas e precariamente organizadas. Isso reafirma a falta de percepção de nossos governantes para com os nossos jovens cegos. Por isso, perguntamos: é possível a inclusão social e escolar desses jovens, sem conhecermos informações detalhadas, como: quantos são, onde moram, faixa etária de maior predominância, o que fazem, escolaridade (aprovação, reprovação, abandono), dentre outros. 
A população total de jovens brasileiros na faixa de 15 a 29 anos é de 51,3 milhões. Os jovens que estão na cidade representam $85 \%$ do total, enquanto que os jovens das áreas rurais totalizam $15 \%$ (IBGE, 2012). Infelizmente, conforme mencionado, não encontramos o total de jovens cegos brasileiros dentre outras informações.

Podemos inferir com base no acentuado analfabetismo da população cega no Brasil que existe descaso do poder público. Acrescentamos a isso a falta de recenseamento dessa população que denota a exclusão do universo de jovens cegos brasileiros.

Os dados do IBGE (2010) sobre o Pará assinalam que esse Estado tem o segundo lugar em percentuais de pessoas cegas na região norte. Dentre as causas congênitas, de acordo com o Relatório (2017), da Fundação Dorinda Nowill para cegos, temos: a amaurose congênita de Leber, malformações oculares, glaucoma congênito, catarata congênita. Dentre as causas adquiridas, temos: traumas oculares, catarata, degeneração senil de mácula, glaucoma, alterações retinianas relacionadas à hipertensão arterial ou diabetes. Dentre os acidentes que mais causam a cegueira em adolescentes e adultos jovens estão os seguintes: o de trânsito, o de atividades esportivas e o do ambiente de trabalho. Não abordaremos essas causas e outras que, embora importantes, não se constituem foco deste estudo.

Mediante esse cenário, existe a urgência de políticas e programas preventivos e de intervenção permanentes que informem, orientem, acolham e incluam as juventudes de cegos do nosso país. Inclui-se nisso, a revitalização e o fortalecimento da Associação de Cegos no Pará para que possam encaminhar as suas demandas ao poder público e procederem as suas lutas.

Outro ponto preocupante é sobre a escolaridade desses jovens cegos. Com base nos dados sobre os jovens brasileiros, no geral, o último Censo, ano de 2017, conforme os dados da Pesquisa Nacional por Amostra de Domicílios (PNAD) indicam que, no Brasil, temos 51,3 milhões de pessoas na faixa de 15 a 29 anos. Desse total, 11,1 milhões deles não trabalhavam, não estavam matriculados em uma escola, ou faculdade, ou curso técnico de nível médio ou de qualificação profissional, dentre outros. Esses números representam $23 \%$ do total de jovens brasileiros.

A variação entre 2016 e 2017 foi de 619 mil jovens de 15 a 29 anos, a maior, nessa condição. O percentual de ocupação de jovens que estudavam e trabalhavam, caiu de $14 \%$ para $13,3 \%$. A porcentagem da população ocupada que só trabalha recuou de $35,7 \%$ para $35 \%$.

Com base nesses dados, podemos pensar que essa queda ocorre em função da crise política que se instalou no país, em meados de 2014. Essa crise política tem rebatimentos na economia e nas questões sociais, educacionais, dentre outras. Consideramos que essa crise, assim como outras

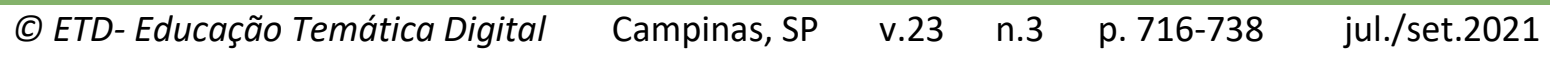


anteriores, tem um impacto maior na Região Norte do país. Com o aumento do desemprego e da inflação, uma parte significativa da população brasileira, sobretudo a do Norte - que já tinha conquistado novos hábitos de consumo e de vida, na medida em que a economia estava aquecida passou a perder as suas conquistas. Com efeito, as condições econômicas e financeiras pioram cada vez mais. O economista da Universidade de Campinas, Bruno de Conti $(2017$, p. 1) declara que "é bem triste verificar como as conquistas sociais, por menores que sejam, vêm de forma gradual, enquanto a destruição é abrupta".

Perguntamos quais as alternativas que esses jovens e, sobretudo, os jovens cegos, buscam para minimizar a situação de falta de estudo e de empregos, pois sabemos que eles são os primeiros e os mais afetados.

Como não temos informações focalizadas nos jovens cegos para que possamos refletir com maior propriedade sobre essas questões mencionadas, hipotetizamos que, em função da diminuição de oportunidades para os jovens de maneira geral, o campo de vulnerabilidade aumenta, ou seja, entendido como fragilidade da situação socioeconômica. Por isso, utilizamos a concepção de Castel $(1998$, p. 26$)$ sobre a vulnerabilidade ao dizer que "é um espaço social de instabilidade, de turbulências, povoado de indivíduos em situação precária em sua relação com o trabalho e frágeis em sua inserção relacional".

Segundo Carmo e Guizardi (2018), o conceito de vulnerabilidade é marcadamente complexo, albergando aspectos econômicos (precário acesso a renda e aos serviços básicos de saúde, de educação, de seguridade social etc.), aspectos subjetivos (autonomia, autorrespeito), dificuldade no acesso ao direito e a proteção social, o que compromete a qualidade de vida.

Essa condição de instabilidade, na visão de Farias (2018, p. 113), "obriga a todo instante as juventudes a fazerem esforços para dar continuidade aos seus processos de escolarização". Acrescentamos nessa mesma linha de pensamento, o trabalho e a realização de seus projetos de vida.

Esses esforços, como observa a pesquisadora mencionada, têm acontecido em um contexto permanente de desigualdades sociais, geradoras de oportunidades heterogêneas. Farias (2018) adverte que os jovens de famílias com rendas mais altas são os que têm índices menores de desemprego, ao mesmo tempo em que os empregos de menores qualificações, geralmente são ocupados pelos jovens do sexo feminino e negros de ambos os sexos, oriundos de famílias com baixa renda e baixa escolaridade.

As marcas deixadas nesses jovens, sobretudo aqueles grupos que lutam duplamente pela escolarização e realização de seus projetos de vida, são a desesperança, as dúvidas sobre o futuro, o afastamento das instituições, bem como a descrença na sua legitimidade e

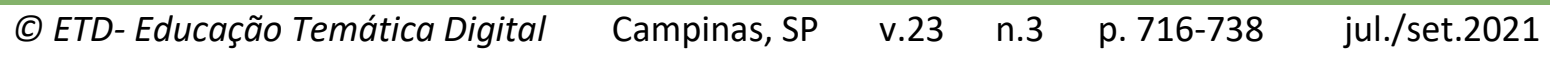


na política formal. Enfim o desestímulo é grande e a frustração, juntamente com a decepção, maior ainda.

Evidenciamos que vivemos em uma sociedade em que o capital é o centro e a determinação de quase todos os apelos. A sociedade contemporânea é caracterizada por Guy Debord (1997), como "sociedade do espetáculo". Esse filósofo, criador desse conceito, define a "sociedade do espetáculo" como "uma relação social entre pessoas, mediada por imagens" (DEBORD, 1997, p. 14). Essas relações sociais, mediadas pelas imagens, se intercruzam com a dramaturgia e com a aparência. Debord (1997) afirma que existe uma interdependência entre o capital e o acúmulo de imagens.

Farias (2018) complementa a concepção de Debord (1997):

Vivemos em um mundo pautado no sistema capitalista, onde a ideia de consumo passou a fazer parte da natureza humana. A busca desenfreada pelo ter, ganhou dimensões inimagináveis, todavia, as necessidades são efêmeras, justamente por conta de serem criadas de acordo com o interesse do capital. (FARIAS, 2018, p. 34).

Juntamente com o ter, estabelece-se o esquecimento da condição existencial, do ser, o que nos torna cada vez mais escravos do capital e das manipulações do comércio. Nesses tempos contemporâneos perversos parece que o humano se desumaniza. Podemos dizer que habitamos uma casa que pensamos ser nossa, mas nos sentimos esvaziados de princípios humanos, esvaziados de ser esvaziados do outro e pelo outro.

Nascimento (2018) sintetiza que:

Em síntese, estamos vivendo um cenário contemporâneo de profundos abalos e mudanças sociais, políticas e econômicas. Esses abalos e mudanças aceleradas anunciam dúvidas, depressões na medida em que os padrões, antes eficazes para diagnosticar, prevenir e solucionar problemas, seja de origem macro e ou micro social, hoje, se colocam ineficazes nessa direção. (NASCIMENTO, 2018, p. 6).

De acordo com a autora e outros estudiosos mencionados, estamos diante de inúmeros desafios que, em nossa análise, se direciona para os princípios e propósitos que regem a dimensão humana, as relações e a estrutura social.

Reiteradamente, perguntamos quais as lutas que o grupo de jovens cegos tem empreendido na direção de suas escolarizações e da realização de seus projetos de vida? Quais as suas conquistas? De igual maneira, pergunto aos jovens cegos que moram no Pará.

Essas questões e outras, que fizemos anteriormente no decorrer da nossa escritura, têm o sentido muito mais de uma provocação para o nosso pensamento do que a intenção de as responder. Para dizê-las, é imprescindível que ouçamos as narrativas desses grupos que, como sinaliza Dayrell $(2009$, p. 23) "[...] antes de tudo, buscar conhecê-los na sua realidade $[\ldots]^{\prime \prime}$.

$\begin{array}{llllll}\text { (C) ETD-Educação Temática Digital } & \text { Campinas, SP } & \text { v.23 } & \text { n.3 } & \text { p. 716-738 } & \text { jul./set.2021 }\end{array}$


Para tanto, significa, neste estudo, apreender as objetivações= imagens e as ancoragens= sentidos que organizam as representações sociais que esses jovens têm sobre seus projetos para poder relacionar a importância que atribuem à escola para a realização desses projetos.

No caso do fenômeno social da inclusão, ele é altamente valorizado e alvo de demanda social daqueles que se encontram à margem. Assim, partimos da premissa de que a inclusão tem uma relação com o estímulo, com as conquistas e com as superações a serem realizadas pelos grupos de jovens cegos. O projeto de vida de jovens tem reflexos de como a inclusão se realizou.

Vale destacar que quando tratamos de inclusão é preciso avaliar a estrutura políticosocial em que a inclusão se insere. Nesse caso, se estamos pensando em inclusão na contemporaneidade brasileira, devemos ter cuidado para não cair nas malhas da (i)racionalidade da inclusão, agenciada pela estrutura neoliberal, implantada no Brasil. Significa que, para a lógica neoliberal, a inclusão tem o sentido de integração. Todas as pessoas devem desenvolver habilidades para gerir suas vidas a partir de seu investimento tanto na escola quanto no mercado e no consumo.

Ao pensarmos na racionalidade da estrutura neoliberal sobre a inclusão na atualidade brasileira, as estratégias se voltam para o auto investimento do sujeito que, segundo Masschelein e Simons (2013, p. 112), são "competências validadas como qualificações, são a moeda (europeia) pelo qual o aluno vitalício - que cuida, organizadamente, da coleta de competências em seu portfólio - expressa a sua empregabilidade social". Desse modo, o sujeito esvazia seu pensamento e suas ações sobre as condições existenciais, vividas para desenvolver potencialidades que o mantenha, além de "incluído", empoderado e valorizado para o mercado e o consumo, onde o dinheiro assume o valor maior do que todos os demais.

Na perspectiva da escuta das narrativas dos jovens cegos sobre o que sabem e como representam seus pensamentos, sentimentos e ações sobre seus projetos de vida, nós pesquisadores, somos convidados para pensar no território, onde essas juventudes se entrelaçam, elaboram representações, se constroem, se sentem incluídos na escola. As questões sociais, econômicas, culturais, educacionais e inclusivas são balizadoras deste estudo. Existe a necessidade de estudos que objetivem as representações sociais de jovens cegos a partir deles. Significa como declara Farias (2018): 
[...] colocá-los como sujeitos produtores de um discurso sobre si mesmos, que revele muito mais da sua existência, projeções, inquietações, medos, desafios, do que se vem construindo em termos de discurso oficial. (FARIAS, 2018, p. 39).

Em síntese, nós educadores podemos contribuir com os jovens de maneira geral e, sobretudo com as juventudes com cegueira, foco deste estudo, escutando suas vozes e estimulando para que elas ecoem suas demandas dentro e fora da escola.

\section{TRAJETÓRIA METODOLÓGICA}

O estudo caracterizou-se por uma pesquisa de abordagem qualitativa, descritiva e interpretativa, cujo objetivo foi o de investigar as representações sociais de jovens com cegueira sobre seus projetos de vida.

Nessa perspectiva, o referencial metodológico utilizado foram os trabalhos de Moreira (2002), que aborda as principais características da pesquisa qualitativa; de Gil (2002) que discute a metodologia do trabalho científico; e de Cervo e Bervian (1983), que conceitua e tipifica a pesquisa descritiva. Entrelaçamos esses referenciais com as concepções desenvolvidas sobre a Teoria da Representação Social por Moscovici (1978; 2002; 2011) e Jodelet (2001), dentre outros afins, para identificar a imagem e os sentidos que o jovem com cegueira tem sobre seus projetos de vida. Além desse referencial, utilizamos outros, necessários para subsidiar a abordagem sobre jovem cego, inclusão, escola e projeto de vida.

A partir desses aportes teóricos e analíticos distintos, percebemos a iniciativa comum desses pesquisadores, em compreender os processos de inclusão a partir da percepção dos próprios sujeitos a serem incluídos.

\subsection{A Seleção da Amostra}

O 'lócus' de nossa pesquisa foi a Unidade Técnica Educacional Especializada José Álvares de Azevedo2 (UTES JAA), instituição paraense voltada à reabilitação pedagógica e social das pessoas com baixa visão e com cegueira. Os sujeitos selecionados obedeceram aos seguintes critérios: a) jovens na faixa etária entre 15 a 29 anos com cegueira congênita ou adventícia; b) que estivessem regularmente matriculados na Unidade Técnica educacional Especializada José Álvares de Azevedo em novembro de 2017; c) que também estivessem matriculados na Educação Básica ou Superior; e d) que aceitassem formalmente o convite para participar da nossa pesquisa. 
Vale ressaltar que a realização da pesquisa que envolve sujeitos, exige procedimentos legais que assegurem os limites éticos dos estudos e garantam a preservação e proteção dos participantes. Para isso, adotamos como base a Resolução 196/1996 que trata dos "[...] referenciais básicos da bioética: autonomia, não maleficência, beneficência e justiça" (BRASIL, 1996, p.1). Nesse sentido, utilizamos o Termo de Consentimento Livre e Esclarecido (TCLE) para colher a assinatura de cada um dos sujeitosvoluntários e respondentes. Para tanto, explicitamos o nosso estudo junto aos jovens que frequentam a Unidade Técnica José Álvares de Azevedo. No segundo momento, abordamos os instrumentos a serem utilizados por nós, seguido do convite para que esses jovens participassem das entrevistas.

Vale destacar que aqueles estudantes que não tivessem a dupla matrícula (na Unidade Especializada e na Educação Básica ou Superior) não foram contemplados pelos critérios estabelecidos pelo estudo realizado. Foram, ainda, excluídos os estudantes com baixa visão, pois o foco do estudo foi o sujeito com cegueira.

A UTEES José Álvares de Azevedo em novembro de 2017 tinha 225 educandos matriculados. Os critérios estabelecidos permitiram a seleção de 29 jovens que poderiam ser convidados para participar do estudo. Optamos por selecionar 10 jovens, o que perfaz $34,5 \%$ de amostra do universo identificado.

\subsection{Dos Instrumentos de Pesquisa aos Procedimentos de Análise}

O instrumento de pesquisa utilizado foi a entrevista com roteiro preestabelecido em forma de temáticas. O roteiro integral está organizado em 5 eixos, 5 categorias e respectivas subcategorias, conforme quadro a seguir. 
Quadro 1 - Dados que compõem o roteiro de entrevista

\begin{tabular}{|c|c|c|c|}
\hline EIXO & CATEGORIA & $\begin{array}{c}\text { SUBCATEGORIAS } \\
\text { Pessoais }\end{array}$ & Idade, sexo, naturalidade, endereço, estado civil, escolaridade; \\
\hline $\mathbf{2}$ & Família & $\begin{array}{l}\text { Constituição, número de residentes, renda familiar, tipo de moradia, familiar } \\
\text { mais próximo; }\end{array}$ \\
\hline $\mathbf{3}$ & Escola & $\begin{array}{l}\text { Idade que começou a estudar, tipo de escola (especial, regular), relacionamento } \\
\text { com os colegas e com os profissionais, recursos especializados que usava, } \\
\text { dificuldade de deslocamento, acesso ao material didático, participação nas } \\
\text { atividades pedagógicas desenvolvidas, acolhimento; }\end{array}$ \\
\hline $\mathbf{4}$ & $\begin{array}{l}\text { Aspectos } \\
\text { Gerais }\end{array}$ & $\begin{array}{l}\text { Origem da cegueira (congênita ou adventícia), reação frente a perda da visão, } \\
\text { limitação imposta pela cegueira, segurança e autonomia no deslocamento, } \\
\text { autoimagem, relacionamento social, experiência de preconceito já vivida, } \\
\text { prática de desporto, música e dança, lazer, projeto de vida, habilidades pessoais; }\end{array}$ \\
\hline $\mathbf{5}$ & $\begin{array}{l}\text { Inclusão } \\
\text { Opinião pessoal, influência da inclusão escolar na trajetória individual, } \\
\text { importância da UTES JAA na trajetória socioeducacional, importância da } \\
\text { reabilitação pedagógica, inclusão social. }\end{array}$ \\
\hline
\end{tabular}

Fonte: Elaborado pelos autores, 2018.

O período de realização das entrevistas foi de novembro de 2017 a julho de 2018, e aconteceu simultaneamente com a realização de outras atividades de estudo, tais como: consulta aos dossiês individuais de alguns educandos, leitura de documentos que disciplinam a inclusão social, consultas a obras que discutem esse tema, aperfeiçoamento do roteiro de entrevista e transcrição das entrevistas realizadas.

Cada entrevista durou em torno de 60 minutos, com 17 questões, gravadas em dispositivo móvel (smartphone), convertidas para o formato MP3, e transcritas pessoalmente para permitir que revivêssemos novamente as entrevistas, fizéssemos registros de impressões, reflexões e questionamentos que emergem nesse exercício, ajustássemos os procedimentos e dedicássemos maior cuidado às informações coletadas, relacionando a voz gravada à atitudes, comportamentos dos respondentes, ou tensão vivida pelos respondentes no momento das entrevistas.

Destacamos para este estudo as respostas dos sujeitos entrevistados sobre a temática projeto de vida. Para a apreensão dessa temática, procedemos à análise de conteúdo que se caracteriza como "um conjunto de técnicas de análise das comunicações" (BARDIN, 1997, p. 31), cujo objetivo foi o de identificar o pensamento consensual dos jovens cegos sobre seus projetos de vida. Esse consenso fornece sustentação às objetivações e as ancoragens que organizam as representações sociais desses jovens cegos, articulados com a 
importância que atribuem à escola nessa realização.

Desse modo, realizamos dois agrupamentos de informações desses 10 jovens cegos, distribuídos entre jovens do sexo feminino e jovens do sexo masculino. No entanto, não podemos perder de vista que o gênero perpassa pelas escolhas desses jovens na perspectiva dos papéis e atribuições femininas e masculinas, recorte que deixaremos para uma próxima abordagem.

Nos dois agrupamentos feitos, tantos os jovens do sexo feminino quanto os do sexo masculino desejam cursar o nível Superior. Dentre os cursos, enfatizados para esses jovens, estão: a Psicologia para os do sexo masculino (2/10 dos entrevistados) e o Serviço Social para as do sexo feminino (2/10 dos entrevistados). É interessante notarmos que ambos os cursos, eleitos por esses jovens, em seus objetivos gerais tratam da identificação sobre comportamento humano, resguardadas as suas especificidades. Enquanto o curso de Psicologia contempla o conhecimento psicossocial humano, o curso de Serviço Social tem seu foco na coletividade e integração do indivíduo na sociedade, para tanto, visa entender e analisar os contextos sociais, a sua dinâmica, as dificuldades individuais e as comunitárias, e ainda, as possibilidades de resistência e de superação.

Outro aspecto, marcante no projeto de vida desses jovens cegos, é a formação em música na perspectiva de poder tocar um instrumento, produzir músicas, fazer apresentações musicais (5/10 dos entrevistados). Essa escolha, em destaque para esses jovens, possivelmente deve-se ao incentivo da família para essa atividade. Oliveira e Rely (2014) afirmam que a imagem do músico cego faz parte do imaginário popular. Segundo os autores, o argumento que sustenta o mito da habilidade musical da pessoa cega reside na crença de que na falta da visão, a sensibilidade auditiva é desenvolvida, facilitando a aprendizagem da música. Oliveira e Reily (2014) declaram:

Em síntese, os participantes reconhecem o apoio da família nos seguintes aspectos: o incentivo, como fabricar instrumentos de brinquedo ou presentear com instrumentos adequados para a criança; ambiente musical; disponibilidade para prover aulas de música; ajuda com transcrição de material musical. (OLIVEIRA; REILY, 2014, s/p)

Os autores dizem que o incentivo da família no desenvolvimento das habilidades musicais, o ambiente musical, a promoção de atividades de aprendizagem de instrumentos musicais e a disponibilidade em transcrever material didático são aspectos que influenciam no interesse pela música e as habilidades dessas pessoas nessa atividade cultural.

Outra dimensão que surge, em grande medida no projeto de vida desses jovens entrevistados, é o trabalho com crianças abandonadas e pessoas com problemas. Consideramos que esse trabalho é uma forma de espelhamento, ou seja, realizar esse

$\begin{array}{llllll}\text { (C) ETD-Educação Temática Digital } & \text { Campinas, SP } & \text { v.23 } & \text { n.3 } & \text { p. 716-738 } & \text { jul./set.2021 }\end{array}$ 
trabalho junto a essas pessoas que de alguma forma necessitam de apoio para desenvolverem-se e aprenderem que, além de ter um aspecto de identificação, tem também o sentimento de esperança e crença de que essas pessoas podem fazer superações assim como eles; os jovens cegos que puderam fazer e ainda fazem superações a despeito dos preconceitos existentes na sociedade atual.

A grande preocupação desses jovens com cegueira em relação ao futuro é a vida profissional, visto que esses escolares desejam um bom emprego, uma boa colocação no mercado e, consequentemente, bons salários. Por mais que o futuro para esses jovens com cegueira seja uma interrogação, eles alimentam perspectivas em seus projetos de vida, sobretudo no futuro.

No entanto, mesmo constatando que nos dias atuais já existem jovens e adultos cegos qualificados e com o nível Superior e outros que buscam se qualificar, essa realidade ainda é restrita e, mesmo assim, esbarra, sobremaneira, nas dificuldades de inseri-los no mercado de trabalho. É comum depararmos com profissionais com cegueira altamente qualificados, ocupando cargos, onde essa qualificação não é exigida e nem utilizada (MEC, 2016).

A escola, na concepção desses jovens entrevistados, é fundamental para a realização de seus projetos de vida. Contudo, é necessário que a escola seja inclusiva e, na visão desses sujeitos, priorize aspectos, como: a formação do professor da sala de aula para trabalhar com a inclusão escolar, além da formação e do serviço do professor de apoio; o uso de metodologias que sejam adequadas a aprendizagem desses alunos e sua autonomia; a acessibilidade nas dependências da escola e nos seus arredores. Além desses aspectos, na visão desses jovens, a escola deve estimular o protagonismo desses sujeitos cegos com atividades extraclasse para o desenvolvimento de habilidades necessárias para a vida e auxiliar a família nesses e outros aspectos.

A certeza de que a educação é fundamental para a realização de seus projetos de vida, comparece nas imagens e sentidos que organizam as representações sociais desses jovens com cegueira. Essa educação escolar, segundo esses jovens, deve prepará-los e possibilitar seus protagonismos para que lutem pelas suas demandas enquanto grupo social, como: pela acessibilidade urbana; pelas oportunidades de lazer, cultura, trabalho e saúde de qualidades; pelo acesso às tecnologias assistivas, dentre outros que, muito embora, se constituam direitos regidos por leis, mas que permanecem sem ação.

Constatamos que os jovens deste estudo se encontram no Ensino Médio (7/10 dos entrevistados), cujo problema não se constitui apenas em ingressar, mas em terminá-lo e chegar ao curso Superior, como observa Nascimento (2002). Esses jovens consideram que a

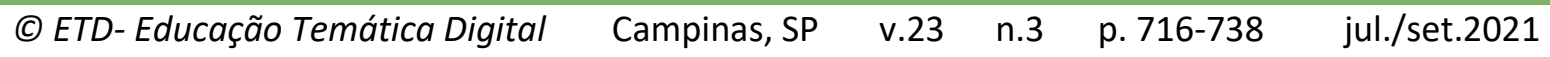


escola é o caminho para conhecer e saber, assim como para ingressar no nível Superior de ensino, trabalhar, obter uma vida melhor e autônoma.

\section{APROXIMAÇÕES CONCLUSIVAS}

O estudo desenvolvido teve por objetivo investigar as representações sociais de jovens com cegueira sobre seus projetos de vida. Nessa perspectiva, algumas inferências puderam ser elaboradas, a partir do conjunto das análises realizadas, conforme destacamos a seguir:

- A centralidade dos Projetos de Vida dos jovens cegos deste estudo reside nas imagens e significados que transitam entre Educação e o Emprego.

- Os jovens cegos entrevistados destacam a relevância da trajetória escolar para a inserção no mercado de trabalho, pontuando a necessidade da formação escolar, acadêmica e profissional para desenvolver as habilidades necessárias para o bom desempenho laboral na carreira que pretendem.

- Para além de aspirarem as condições dignas de vida, resultante do trabalho que almejam desenvolver, estes jovens também alimentam a esperança de contribuir para o bem-estar daqueles que irão atender, colaborar no desenvolvimento da sociedade e contarem com o reconhecimento social.

- Outra inferência refere-se as representações sociais desses jovens sobre seus projetos de vida, as quais se organizam a partir de quatro dimensões: a sociocognitiva, a socioafetiva, a histórico-social e a socioeducacional. Estas organizam os processos de objetivação e a ancoragem responsável pela construção das representações sociais de jovens sobre seus projetos de vida (NASCIMENTO, 2002). Os jovens entrevistados compreendem a importância da aprendizagem para o seu aperfeiçoamento humano, social, técnico e político e sabem a relevância que assumem em seu projeto de futuro.

- Compreendem que a incapacidade visual que têm impõe sérias limitações e dificuldades para a trajetória escolar e profissional deles, mas também acreditam que com o apoio, recursos e condições adequadas, as quais respeitem as suas necessidades e características pessoais, são capazes de conviverem com a cegueira e desenvolver as atividades que esperam deles.

A escola por um lado é representada no discurso dos jovens cegos como importante e fundamental, porém sem ressignificar a racionalidade com a qual materializa o processo ensino-aprendizagem, passa a representar um obstáculo por suas condições de ensino. Em síntese, o descompasso entre os contextos sócio-históricos, nos quais as juventudes se constroem e a educação que recebem, é preocupante, uma vez que fortalece o campo de 
vulnerabilidades, onde essas juventudes podem se inserir, segundo Nascimento e Rodrigues (2018).

As políticas públicas socioeducacionais para jovens cegos são fundamentais para a inclusão, para as aprendizagens e para o desenvolvimento de habilidades de vida e acadêmicas assim como a realização de seus projetos de vida. As políticas públicas que promovam a inclusão social e a acessibilidade no espaço educacional, no mercado de trabalho e nos diversos setores socioculturais facilitam a interação com este grupo, ampliam as oportunidades de ocupação laboral e de respeito às necessidades específicas dos mais diversos grupos sociais.

Dessa forma, a responsabilidade da inclusão escolar de jovens cegos e de outros grupos sociais é de todos os que participam da sociedade, sobretudo aqueles que se encontram na linha de frente da dimensão educacional do país. Os princípios, a política e as práticas inclusivas comprometem todos os setores sociais e exigem a superação de velhos procedimentos, pautados na segmentação e na segregação de grupos historicamente excluídos. A inclusão social é um processo que reivindica o avanço, o aperfeiçoamento e o envolvimento de todos.

O campo educacional assume importância vital nesse processo, seja pelo espaço que ocupa na formação social, cultural, técnica dos sujeitos, seja por se constituir em um dos primeiros grupos sociais que todos participam. Isto faz com que o papel do professor, as relações que se desenvolvem nas escolas, o desenvolvimento da aprendizagem e as condições de funcionamento das escolas sejam fortemente evidenciadas, o que amplia as expectativas dos jovens cegos quanto a sua relevância no projeto de vida deles.

Por fim, vale dizer que a lógica Neoliberal convoca todos para a participação nas esferas sociais e econômicas, no entanto, ao responsabilizar o indivíduo pelo seu sucesso ou fracasso pessoal na interação com a sociedade, sem assegurar as condições necessárias ao desenvolvimento humano, social e profissional, eleva os níveis da competição brutal e desenfreada, produzindo uma multidão de indivíduos ávidos por consumir, por atender ao clamor do mercado, desconectados das mais essenciais características do ser humano.A inclusão social se contrapõe frontalmente a esses princípios e procedimentos e exige que não se perca de vista os propósitos almejados pelo projeto de uma sociedade efetivamente inclusiva. 


\section{REFERÊNCIAS}

AINSCOW, Mel; FERREIRA, Windyz. Compreendendo a educação inclusiva: algumas reflexões sobre experiências internacionais. In: RODRIGUES, David (Org.). Perspectivas sobre a inclusão: da educação à sociedade. Porto: Porto Ed., 2003. p. 103-116.

BARDIN, Laurence. Análise de conteúdo. São Paulo: Edições 70, 2011.

BRASIL. Lei no 12.852, de 5 de agosto de 2013. Institui o Estatuto da Juventude e dispõe sobre os direitos dos jovens, os princípios e diretrizes das políticas públicas de juventude e o Sistema Nacional de Juventude - SINAJUVE. Brasília, DF: Presidência da República.

Disponível em: http://www.planalto.gov.br/CCIVIL 03/ Ato20112014/2013/Lei/L12852.htm-- . Acesso em: 11 ago. 2019.

BRASIL. Decreto no 5.296, de 2 de dezembro de 2004. Regulamenta as Leis n. 10.048, de 8 de novembro de 2000, que dá prioridade de atendimento às pessoas que especifica, e 10.098, de 19 de dezembro de 2000, que estabelece normas gerais e critérios básicos para a promoção da acessibilidade das pessoas portadoras de deficiência ou com mobilidade reduzida, e dá outras providências. Brasília, DF: Presidência da República. Disponível em: http://www.planalto.gov.br/ccivil 03/ ato2004-2006/2004/decreto/d5296.htm . Acesso em: 11 ago. 2019.

$\mathrm{BERSCH}$, Rita de Cassia Reckziegel et al. Formação continuada à distância de professores para o atendimento educacional especializado. Deficiência Física. São Paulo: MEC/SEESP, 2007.

BOURDIEU, Pierre. O poder simbólico. Rio de Janeiro: DIFEL, 1989.

CARMO, Michelly Eustáquia do; GUIZARDI, Francini Lube. O conceito de vulnerabilidade e seus sentidos para as políticas públicas de saúde e assistência social. Cad. Saúde Pública, Brasília, v. 34, n. 3, p. 1-14, 2018.

CASTEL, Robert. La dynamique des processos de marginalisation: de la vulnerabilité à la désaffiliation. Cahiers de recherche sociologique, Paris, n. 22, p. 11-27, 1994.

CATÃO, Maria de Fátima. Projeto de vida em construção: na exclusão/inserção social. João Pessoa: UFPB Universitária, 2001.

CERVO, Amado Luiz; BERVIAN. Pedro Alcino. Metodologia científica: para uso dos estudantes universitários. São Paulo: McGraw-Hill do Brasil, 1983. 
CONTI, Bruno. Brasil enfrenta pior crise já registrada poucos anos após um boom econômico. O Globo, 7 jul. 2017. Disponível em: https://g1.globo.com/economia/noticia/br asil-enfrenta-pior-crise-ja-registrada-poucos-anos-apos-um-boom-economico.ghtml. Acesso em: 25 jul. 2019.

CARRANO, Paulo Cesar Rodrigues. Identidades culturais juvenis e escolas: arenas de conflitos e possibilidades. In: MOREIRA, Antônio Flávio; CANDAU, Vera Maria (Org). Multiculturalismo: diferenças culturais e práticas pedagógicas. 10. ed. Petrópolis: Vozes, 2013. p.182-211.

CORREIA, Luís de Miranda. Necessidades educativas especiais na sala de aula. Porto: Porto Editora, 1999.

DAYRELL, Juarez. A escola faz as juventudes? Reflexões em torno da socialização juvenil, Revista Educação e Sociedade, Campinas, SP, v. 28, n.100, p. 1105-1128, out. 2007. Edição Especial.

DEBORD, Guy. A sociedade do espetáculo. Rio de Janeiro: Contraponto, 1997.

DUARTE, Francisco Ednardo. As representações sociais de universitários de sexualidades LGBT sobre seus processos de escolarização e as implicações em seus projetos de vida. 2015. Tese (Doutorado em Educação) - Instituto de Ciências da Educação, Universidade Federal do Pará, Belém, 2015.

FARIAS, Degiane da Silva. Juventude, escolarização e projeto de vida: representações sociais dos jovens de Bragança/Amazônia Paraense. 2018. Tese (Doutorado em Educação) Instituto de Ciências da Educação, Universidade Federal do Pará, Belém, 2018.

FUNDAÇÃO DORINA NOWILL PARA CEGOS. Estatísticas da deficiência visual no Brasil, 2014. Disponível em: https://www.fundacaodorina.org.br/a-fundacao/deficienciavisual/estatisticas-da-deficiencia-visual/about:blank\&gt . Acesso em: 28 out. 2019.

GALEANO, Eduardo. O livro dos abraços. Porto Alegre: L\&PM, 1991.

GIL, Antônio Carlos. Como elaborar projetos de pesquisa. 4. ed. São Paulo: Atlas, 2002.

INSTITUTO BRASILEIRO DE GEOGRAFIA E ESTATÍSTICA (IBGE). Censo demográfico, 2010. Características gerais da população, pessoas com deficiência. Rio de Janeiro: IBGE, 2010.

INSTITUTO BRASILEIRO DE GEOGRAFIA E ESTATÍSTICA (IBGE). Censo demográfico, 2012. Características gerais da população, pessoas com deficiência. Rio de Janeiro: IBGE, 2012. JODELET, Denise. Representação Sociais: um domínio em expansão. In: JODELET, Denise. As representações sociais. Tradução de Lilian Ulup. Rio de Janeiro: EDUERJ, 2001. p. 17-44.

MASSCHELEIN, Jan; SIMONS, Maarten. Em defesa da escola: uma questão pública. Belo Horizonte: Autêntica, 2013. 
MENDES, Fátima Aparecida Gonçalves. A constituição de sujeitos com cegueira adquirida e a aprendizagem da leitura e escrita braille. 2014. Dissertação (Mestrado em Educação) Programa de Pós-Graduação em Educação, Universidade Metodista de Piracicaba, Piracicaba, 2014.

MINISTÉRIO DA EDUCAÇÃO E CULTURA (MEC). O encaminhamento do deficiente visual ao mercado de trabalho, 2016. Instituto Benjamin Constant. Disponível em: http://www.ibc.gov.br . Acesso em: 9 nov. 2019.

MOREIRA, Daniel Augusto. O método fenomenológico na pesquisa. São Paulo: Pioneira Thomson, 2002.

MOSCOVICl, Serge. A representação social da realidade. Rio de Janeiro: Zahar, 1978.

MOSCOVICl, Serge. Representações sociais. 4. ed. Petrópolis: Vozes, 2002.

MOSCOVICl, Serge. Representações sociais: investigações em psicologia social. 8. ed. Petrópolis: Vozes, 2011.

NASCIMENTO, Ivany Pinto. As Representações Sociais dos Projetos de Vida dos jovens: um estudo psicossocial. 2002. Tese (Doutorado em Psicologia da Educação) - Pontifícia Universidade Católica de São Paulo, São Paulo, 2002.

NASCIMENTO, Ivany Pinto; RODRIGUES, Sônia Eli Cabral. Os jovens na Pós-Modernidade: caleidoscópio de seus projetos de futuro. Revista Educere, Cascavel, v. 13, n. 28, p. 1-26, maio/ago. 2018.

OLIVEIRA, Lorena Maria Mourão de; HAGE, Salomão Antônio Mufarrej. Socioterritorialidade da Amazônia e as políticas de educação do campo. Revista Ver a Educação, Belém, v. 12, n. 1, p. 141-158, jan./jun. 2011.

OLIVEIRA, Leonardo Augusto Cardoso de; REILY, Lucia Helena. Relatos de músicos cegos: subsídios para o ensino de música para alunos com deficiência visual. Revista Brasileira de Educação Especial, Marília, v. 20, n. 3, jul./set. 2014.

PERALVA, Angelina. O jovem como modelo cultural. Revista Brasileira de Educação, São Paulo, n. 5/6, p. 15-24, maio/ dez. 1997.

RAITZ, Tânia Regina; PETTERS, Luciane Carmem Figueiredo. Novos desafios dos jovens na atualidade: trabalho, educação e família. Revista Psicologia \& Sociedade-UFMG, Belo Horizonte, v.20, n.3, p.408-416,.2008.

SPINK, Mary Jane. O estudo empírico das representações sociais. In: SPINK, M. J. (org.) O conhecimento no cotidiano. As representações sociais na perspectiva da psicologia social. São Paulo: Brasiliense, 1993. p. 234-265.

Revisão gramatical realizada por: Ana Conceição Borges de Oliveira E-mail: letras2006@yahoo.com.br

(C) ETD-Educação Temática Digital Campinas, SP $\quad$ v.23 $\quad$ n.3 $\quad$ p.716-738 jul./set.2021

